\title{
LETTER
}

CHRONIC MYELOPROLIFERATIVE NEOPLASMS

\section{Single dose of BNT162b2 mRNA vaccine against SARS-CoV-2 induces high frequency of neutralising antibody and polyfunctional T-cell responses in patients with myeloproliferative neoplasms}

\author{
Patrick Harrington $\mathbb{D}^{1,2} \cdot$ Hugues de Lavallade ${ }^{1,2,3} \cdot$ Katie J. Doores ${ }^{4} \cdot$ Amy O'Reilly $\mathbb{D}^{1} \cdot$ Jeffrey Seow ${ }^{4}$. \\ Carl Graham $^{4}$ - Thomas Lechmere ${ }^{4}$ Deepti Radia ${ }^{1} \cdot$ Richard Dillon $^{1,5} \cdot$ Yogita Shanmugharaj $^{1}$. \\ Andreas Espehana $\mathbb{D}^{1} \cdot$ Claire Woodley $^{1} \cdot$ Jamie Saunders $^{1}{ }^{1} \cdot$ Natalia Curto-Garcia $^{1} \cdot{\text { Jennifer } \mathbf{O}^{\prime} \text { Sullivan }}^{1}$. \\ Kavita Raj ${ }^{1}$ - Shahram Kordasti ${ }^{1,2}$ - Michael H. Malim ${ }^{4}$. Claire N. Harrison ${ }^{1,2}$ - Donal P. McLornan ${ }^{1,2}$
}

Received: 23 April 2021 / Revised: 4 May 2021 / Accepted: 12 May 2021 / Published online: 22 May 2021

(c) The Author(s), under exclusive licence to Springer Nature Limited 2021

\section{To the Editor:}

Encouraging results have been observed from initial studies evaluating vaccines targeting the novel beta coronavirus which causes severe acute respiratory syndrome coronavirus 2 (SARS-CoV-2) [1, 2]. BNT162b2 (Pfizer- BioNTech) is a nucleoside-modified mRNA that encodes a full-length SARS-CoV-2 Spike (S) protein, a key target of neutralising antibodies, and has demonstrated a $95 \%$ reduction of cases in the general population [1]. However, concerns have been raised around the efficacy of these vaccines in immunosuppressed populations, including patients with haematological malignancy [3].

Myeloproliferative neoplasms (MPN), in particular myelofibrosis (MF), are associated with a pro-inflammatory state and dysregulation of pivotal natural killer cell, regulatory $\mathrm{T}$ cell and effector $\mathrm{T}$ cell function $[4,5]$. These heterogenous defects are further influenced by patient age, disease subtype, stage and the use of cytoreductive

Donal P. McLornan

Donal.mclornan@nhs.net

1 Department of Clinical Haematology, Guy's \& St Thomas' NHS Foundation Trust, London, UK

2 School of Cancer and Pharmaceutical Science, King's College London, London, UK

3 Department of Haematological Medicine, King's College London School of Medicine, London, UK

4 Department of Infectious Diseases, School of Immunology \& Microbial Sciences, King's College London, London, UK

5 Department of Medicine and Molecular Genetics, King's College London, London, UK therapies, including JAK inhibitors [4]. A recently reported large scale population-based cohort study found incidence of both bacterial and viral infections to be significantly increased in MPN patients, irrespective of the use of cytoreductive therapies [6]. Another large patient reported prospective study evaluating incidence of infection in MPN patients found both a diagnosis of MF and the use of ruxolitinib therapy to be associated with increased risk of infection [7]. Separately, a study evaluating MF patients treated with ruxolitinib found disease severity, as determined by high international prognostic score system category, to be significantly correlated with infectious risk, with an optimal spleen response to treatment associated with improved infection free survival [8]. These studies highlight the importance of an effective vaccination programme against SARS-CoV-2 in this population. Herein we describe, for the first time, immune responses to the first injection of BNT162b2 in an unselected MPN cohort.

Patients with a WHO defined diagnosis of an MPN presenting to our clinic were recruited in accordance with the regional research and ethics review board, with sampling at baseline and median of 21 days (IQR 21-21) following first injection of $30 \mu \mathrm{g}$ BNT162b2. Clinical characteristics and adverse events are summarised in Table 1, with all adverse events reported within 7 days after administration of the vaccine considered to be related to the vaccine. The vaccine was safe and generally well tolerated with $57.1 \%$ (12) patients reporting localised inflammation and $47.6 \%$ (10) of patients reporting systemic side effects including flu-like illness, fatigue and gastrointestinal symptoms, following injection

Anti-S IgG ELISA testing was performed as described previously [9] in all 21 patients and results were compared with samples taken prior to vaccination in 20 patients. 


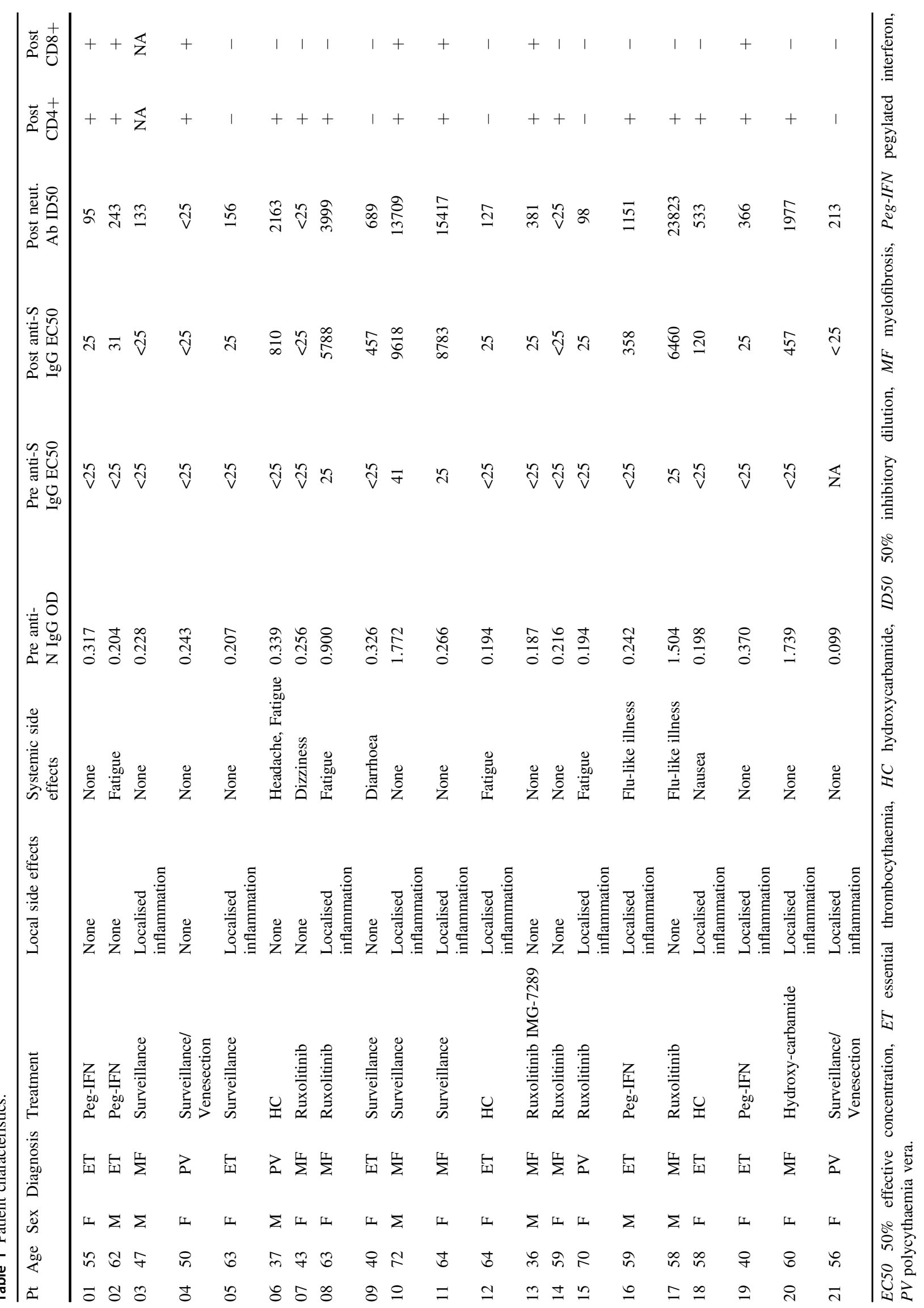


MF patient on Ruxolitinib

a) CD4+ T cells

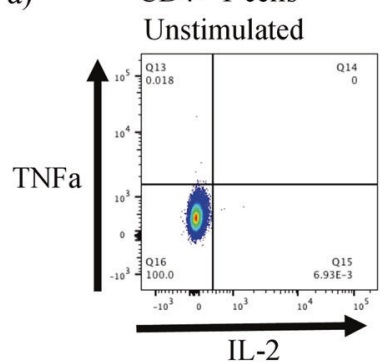

MF patient on Ruxolitinib

b) CD8+ T cells

Unstimulated

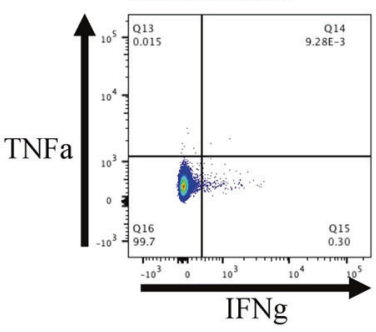

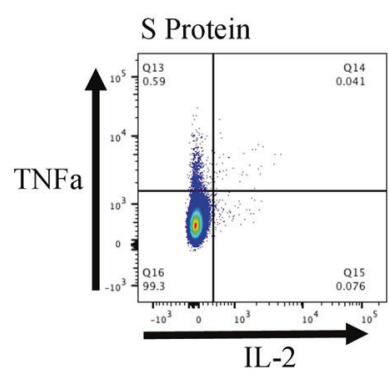

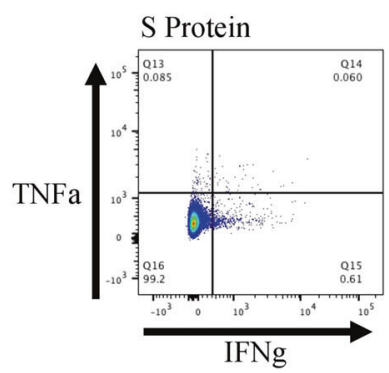

c)

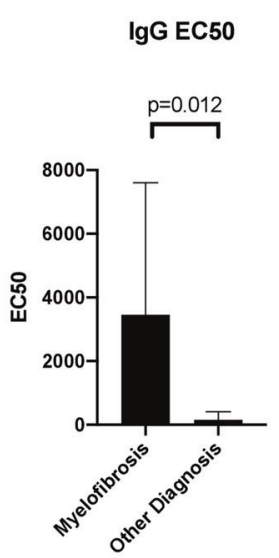

d)

Neutralising Ab ID50

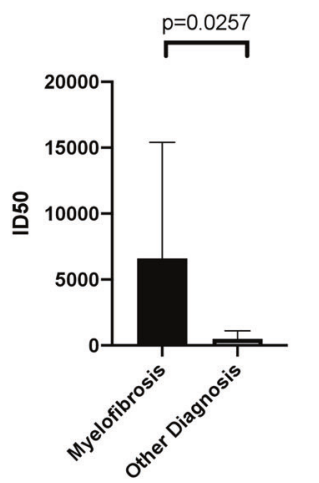

Fig. 1 Representative $\mathbf{T}$ cell and antibody responses. a Post-vaccine polyfunctional $\mathrm{CD} 4+\mathrm{T}$ cell response in MF patient on ruxolitinib showing TNF $\alpha$ and IL-2 expression in unstimulated cells (left) and cells exposed to S protein (right). b Post-vaccine polyfunctional CD8 $+\mathrm{T}$ cell

Neutralising antibody analysis was also performed in postvaccine samples from all 21 patients. Briefly, HIV-1 (human immunodeficiency virus type-1) based virus particles, pseudotyped with SARS-CoV-2 Wuhan Spike were prepared in HEK-293T/17 cells and neutralisation assays were conducted as previously described [10]. Serial dilutions of heat inactivated plasma samples were prepared in DMEM complete media and incubated with pseudotyped virus for $1 \mathrm{~h}$ at $37^{\circ} \mathrm{C}$ in 96-well plates. Next, HeLa cells stably expressing the ACE2 receptor (provided by Dr James Voss, Scripps Research, La Jolla, CA) were added and the plates were left for $72 \mathrm{~h}$. Infection level was assessed in lysed cells with the Bright-Glo luciferase kit (Promega), using a Victor ${ }^{\mathrm{TM}} \mathrm{X} 3$ multilabel reader (Perkin Elmer). Measurements were performed in duplicate and the duplicates used to calculate the serum dilution that inhibits $50 \%$ infection $\left(\mathrm{ID}_{50}\right)$ using GraphPad Prism.

At baseline, four patients showed evidence of prior infection with positive anti-nucleocapsid IgG ELISA and an additional patient was positive for anti-S IgG. A positive anti-S IgG ELISA was seen in $76.1 \%$ (16) of patients following vaccination. The median anti-S IgG EC50 amongst positive samples was 239 (IQR 25-4544). Positive neutralising antibodies were detected in $85.7 \%$ (18) of patients, with a median ID50 of 457 (IQR 150.3-2622). Moreover, high (>501) neutralising titres were observed in $42.9 \%$ (9) of patients. response in MF patient on ruxolitinib showing TNF $\alpha$ and IFN $\gamma$ expression in unstimulated cells (left) and cells exposed to $S$ protein (right). c IgG EC50 in MF patients compared with other diagnoses. d Neutralising antibody ID50 in MF patients compared with other diagnoses.

The induction of virus-specific T-cell responses by BNT162b2 vaccination was assessed ex-vivo by flow cytometric enumeration of antigen-specific CD8+ and CD4+ T lymphocytes using an intracellular cytokine assay for IFN $\gamma$, TNF $\alpha$ and IL2, as described [11]. Briefly, cells were thawed, then rested for $18 \mathrm{~h}$ at $37^{\circ} \mathrm{C}, 5 \% \mathrm{CO} 2$. Specific peptides covering the immunogenic domains of the Spike (S) protein (Miltenyi Biotech) $(0.25 \mu \mathrm{g} / \mathrm{ml})$ and antiCD28 (BD bioscience) were added for $3 \mathrm{~h}$, followed by Brefeldin-A (BFA) for an additional $3 \mathrm{~h}$. Unstimulated cells were utilised as negative controls and PMA and Ionomycin (Miltenyi Biotech) was added separately as a positive control. Cells were stained with a viability dye, stained with antibodies directed against surface markers, and fixed and permeabilised (BD CytoFix/Cytoperm) prior to staining with antibodies directed against intracellular cytokines.

$\mathrm{T}$ cell analysis was performed in 20 patients with a response considered positive if there was a threefold increase in any pro-inflammatory cytokine from baseline expression, and above a threshold of 0.01 . A memory $\mathrm{T}$ cell response was observed in $80 \%$ (16) of patients, with a $\mathrm{CD} 4+\mathrm{T}$ cell response in $75 \%$ (15) and a CD8 $+\mathrm{T}$ cell response in $35 \%$ (7). A polyfunctional $\mathrm{T}$ cell response was observed in $65 \%$ (13) of patients evaluated (Fig. 1a, b). The median increase in expression of $\mathrm{TNF} \alpha$ in $\mathrm{CD} 4+$ cells compared with the baseline unstimulated control was 0.07 (IQR 0.01-0.35) and in CD8+ cells 0.11 (0.00-0.19). 
Median increase in IFN $\gamma$ expression was $0.04(-0.01$ to $0.1)$ in CD4+ and 0.09 ( -0.01 to 0.3$)$ in CD8+ cells, whilst IL-2 was 0.05 (0.01-0.34) in CD4 and $0.02(0.00-0.19)$.

Of note, patients with a diagnosis of MF $(n=9)$ had significantly higher post-vaccine anti-S IgG EC50 and neutralising antibody ID50 titres compared to patients with other MPN subtypes, with a mean IgG EC50 of 3459 vs $158.4(p=0.012)$ and mean ID50 of 6604 vs 486.2 $(p=0.026)$ respectively (Fig. 1c, d). However, four of the patients with evidence of previous Covid-19 infection also had a diagnosis of MF. No significant differences in T cell or antibody response were identified between patients on treatment compared with those undergoing active surveillance. Similarly, no significant differences were observed between those taking ruxolitinib, compared with other therapies.

These results, for the first time, provide some reassurance regarding the initial immune response to the BNT162b2 vaccine amongst patients with MPN, with response rates similar to that observed in the general population [12]. This is particularly relevant following reports of a reduced response to a first injection of BNT162b2 in a heterogeneous group of cancer patients, with predominantly solid tissue and lymphoid malignancies. A memory $\mathrm{T}$ cell response may prove to be particularly important with regards to ongoing immunity against SARS-CoV-2. Our group has demonstrated a marked decline in neutralising antibodies in the 3 months following infection [7], whilst a robust $\mathrm{T}$ cell response remains evident at 6 months post infection [8]. Indeed, evidence from the SARS-CoV-1 epidemic showed the memory $\mathrm{T}$ cell response to be significantly more durable than antibodies [13, 14].

Further analyses of the immune response to a second injection of BNT162b2, as well as the response to other vaccines against SARS-CoV-2, are clearly required. Longitudinal studies will also need to assess the durability of these responses and confirm that vaccination translates into a reduction in cases in this population.

Acknowledgements $\mathrm{PH}$ designed the research, performed the research, analysed the data and wrote the manuscript. KJD, JSe, CG, TL and MHM perfomed the research and reviewed the manuscript. DR, RD, CW, JSa, NCG, JOS, KR and SK assisted with patient recruitment and reviewed the manuscript. AOR, YS and AE assisted with patient recruitment, patient interviews and reviewed the manuscript. HdL, CH and DM designed the research, assisted with patient recruitment, analysed the data and wrote the manuscript.

Funding King's Together Rapid COVID-19 Call awards to MHM, KJD; A Huo Family Foundation Award to MHM, KJD; Chronic Disease Research Foundation award CDRF-22/2020 to KJD, MHM; part of the EDCTP2 programme supported by the European Union (RIA2020EF-3008 COVAB) to KJD, MHM; MRC Genotypeto-Phenotype UK National Virology Consortium (MR/W005611/1) to MHM, KJD; Wellcome Trust Investigator Award 106223/Z/14/Z to MHM; CG was supported by the MRC-KCL Doctoral Training
Partnership in Biomedical Sciences (MR/N013700/1); Fondation Dormeur, Vaduz for funding equipment to KJD; MPN Voice Grant to $\mathrm{CH}$ and DM.

\section{Compliance with ethical standards}

Conflict of interest PH reports research funding from Bristol Myers Squibb and speakers fees from Incyte. HdL has received research grants and honoraria from Incyte and honoraria from Novartis and Pfizer. CH has received speaker fees from Novartis, Jannsen, CTI, Celgene, Medscape and has served on the Advisory Board for Incyte, CTI, Sierra Oncology, Novartis, Celgene, Roche, AOP pharma, Geron and Astra Zenica. DM has received speaker fees and advisory boards Novartis, Celgene and Jazz pharmaceuticals.

Publisher's note Springer Nature remains neutral with regard to jurisdictional claims in published maps and institutional affiliations.

\section{References}

1. Polack FP, Thomas SJ, Kitchin N, Absalon J, Gurtman A, Lockhart S, et al. Safety and efficacy of the BNT162b2 mRNA Covid-19 vaccine. N. Engl J Med. 2020;383:2603-15.

2. Voysey M, Clemens SAC, Madhi SA, Weckx LY, Folegatti PM, Aley PK, et al. Safety and efficacy of the ChAdOx1 nCoV-19 vaccine (AZD1222) against SARS-CoV-2: an interim analysis of four randomised controlled trials in Brazil, South Africa, and the UK. Lancet. 2021;397:99-111.

3. Monin-Aldama L, Laing AG, Muñoz-Ruiz M, McKenzie DR, del Molino del Barrio I, Alaguthurai T, et al. Interim results of the safety and immune-efficacy of 1 versus 2 doses of COVID-19 vaccine BNT162b2 for cancer patients in the context of the UK vaccine priority guidelines. medRxiv. 2021. https://doi.org/10. 1101/2021.03.17.21253131.

4. McLornan DP, Khan AA, Harrison CN. Immunological consequences of JAK inhibition: friend or foe? Curr Hematol Malignancy Rep. 2015;10:370-9.

5. Heine A, Held SAE, Daecke SN, Wallner S, Yajnanarayana SP, Kurts C, et al. The JAK-inhibitor ruxolitinib impairs dendritic cell function in vitro and in vivo. Blood. 2013;122:1192-202.

6. Landtblom AR, Andersson TM, Dickman PW, Smedby KE, Eloranta S, Batyrbekova N, et al. Risk of infections in patients with myeloproliferative neoplasms-a population-based cohort study of 8363 patients. Leukemia. 2021;35:476-84.

7. Crodel CC, Jentsch-Ullrich K, Koschmieder S, Kämpfe D, Griesshammer M, Döhner K, et al. Frequency of infections in 948 MPN patients: a prospective multicenter patient-reported pilot study. Leukemia 2020;34:1949-53. https://doi.org/10.1038/s41375-020-0890-1.

8. Polverelli N, Palumbo GA, Binotto G, Abruzzese E, Benevolo G, Bergamaschi M, et al. Epidemiology, outcome, and risk factors for infectious complications in myelofibrosis patients receiving ruxolitinib: A multicenter study on 446 patients. Hematol Oncol. 2018;36:561-9.

9. Pickering S, Betancor G, Galao RP, Merrick B, Signell AW, Wilson HD, et al. Comparative assessment of multiple COVID-19 serological technologies supports continued evaluation of pointof-care lateral flow assays in hospital and community healthcare settings. PLoS Pathog. 2020;16:e1008817.

10. Seow J, Graham C, Merrick B, Acors S, Pickering S, Steel KJA, et al. Longitudinal observation and decline of neutralizing antibody responses in the three months following SARS-CoV-2 infection in humans. Nat Microbiol. 2020;5:1598-607. 
11. Harrington P, Harrison CN, Dillon R, Radia DH, Rezvani K, Raj K, et al. Evidence of robust memory T-cell responses in patients with chronic myeloproliferative neoplasms following infection with severe acute respiratory syndrome coronavirus-2 (SARS-CoV-2). Br J Haematol. 2021;193:692-6.

12. Sahin U, Muik A, Derhovanessian E, Vogler I, Kranz LM, Vormehr M, et al. COVID-19 vaccine BNT162b1 elicits human antibody and TH1 T cell responses. Nature. 2020;586:594-9.
13. Yang LT, Peng H, Zhu ZL, Li G, Huang ZT, Zhao ZX, et al. Long-lived effector/central memory T-cell responses to severe acute respiratory syndrome coronavirus (SARS-CoV) S antigen in recovered SARS patients. Clin. Immunol. 2006;120:171-8.

14. Channappanavar R, Fett C, Zhao J, Meyerholz DK, Perlman S. Virus-specific memory CD8 $\mathrm{T}$ cells provide substantial protection from lethal severe acute respiratory syndrome coronavirus infection. J Virol. 2014;88:11034-44. 